\title{
Bothrops erythromelas snake venom induces a proinflammatory response in mice splenocytes
}

This article was published in the following Dove Press journal:

International Journal of Interferon, Cytokine and Mediator Research

25 January 2011

Number of times this article has been viewed

Karla PO Luna ${ }^{1,2}$

Cristiane ML Melo'

Vanessa PM Pascoal ${ }^{3}$

Olindo A Martins-Filho ${ }^{3}$

Valéria RA Pereira'

'Departamento de Imunologia, Instituto Aggeu Magalhães FIOCRUZ, Pernambuco, Brazil; ${ }^{2}$ Universidade Estadual da Paraíba, Campina Grande, Brazil; ${ }^{3}$ Centro de Pesquisas René Rachou - FIOCRUZ, Minas Gerais, Brazil
Correspondence: Valéria Rêgo Alves Pereira

Departamento de Imunologia, Centro de Pesquisas Aggeu Magalhães,

Av Moraes Rego s/n, Cidade

Universitária, CEP: 50670-420,

Recife, Pernambuco, Brazil

Tel $+558|2| 0|263|$

Fax +558121012640

Email valeriaph@gmail.com
Abstract: Snake venom is a complex biological mixture used for immobilization and killing of prey for alimentation. Many effects are inflicted by this venom, such as coagulation, necrosis, bleeding, inflammation, and shock. This study aimed to evaluate the inflammatory activity promoted by Bothrops erythromelas and Crotalus durissus cascavella snake venom. It was observed that both $B$. erythromelas and $C$. $d$. cascavella venom induced higher interferon-gamma and interleukin-6 production. Nitric oxide (NO) was significantly produced only by $B$. erythromelas venom, which also showed a higher rate of cell death induction when compared with $C$. d. cascavella. Results showed that B. erythromelas and $C$. d. cascavella venom induced distinct response in vitro through cytokines and NO production. However, $B$. erythromelas induces a proinflammatory response and a higher rate of cell death in relation to C. d. cascavella venom.

Keywords: snake venom, Bothrops, nitric oxide, necrosis, Crotalus

\section{Introduction}

Snake envenomation is a health problem mainly in rural areas of tropical and subtropical countries. ${ }^{1,2}$ In Brazil, 20,000 bites by venomous snakes are reported each year, approximately $90 \%$ of which are inflicted by the genus Bothrops. ${ }^{3}$ People bitten by Bothrops species manifest local and systemic manifestations like edema, pain, ecchymosis, blisters, myonecrosis, gingival bleeding, hematuria, epistaxis, hemorrhage, and leukocyte infiltration., ${ }^{4,5}$

The genus Crotalus contains several species of snakes, such as Crotalus durissus cascavella (usually found in scrublands of the Brazilian northeast), which is responsible for approximately 1500 cases of snakebite annually. ${ }^{6,7}$ Crotalus species envenomation is caused by a complex mixture of biologically active substances, such as toxins, enzymes, and peptides. ${ }^{8}$ Clinical manifestations induced by Crotalus venom in South America are neurotoxicity, myotoxicity, and renal damage. The venom also has antithrombotic, plateletaggregating activities and an analgesic effect and can cause acute renal failure. ${ }^{9-11}$

Many studies show that the venom of different snakes induces specific immunomodulatory responses in vitro and in vivo. ${ }^{12-14}$ These responses are divided between T-helper 1 (Th1) and Th2 cells and are mediated by specific cytokines that determine effective functions of immune system compounds. ${ }^{15}$ Different cytokines are involved in both Th1 and Th2 responses. Interleukin-2 (IL-2) has multiple, sometimes opposing, functions during an inflammatory response and is a potent inducer of T-cell proliferation and Th1 and Th2 effector T-cell differentiation. ${ }^{16}$ IL-6 is a critical factor for hematopoiesis through regulation of the entry of hematopoietic stem cells 
into the cell cycle, proliferation of cells committed to the myeloid and lymphoid lineage, and maturation of B-cells into antibody-producing cells. ${ }^{17} \mathrm{IL}-10$ is an important immunoregulatory cytokine that influences innate and adaptive immune responses. ${ }^{18}$ Interferon-gamma (IFN- $\gamma$ ) is a cytokine secreted by activated $\mathrm{T}$ and natural killer cells and regulates host defense, inflammation, and autoimmunity. The balance of these cytokines determines which response is predominant, whether Th1 or Th2. ${ }^{19}$

Ophidian envenomation induces physiological and immunological consequences. To investigate the immunomodulatory response induced by both Bothrops erythromelas and $C$. $d$. cascavella Brazilian snake venom, the present study analyzed nitric oxide (NO), IL-2, IL-6, IL-10, and IFN- $\gamma$ production on stimulated mice splenocyte cultures. Cytotoxic assays and cell viability tests were also performed to evaluate, when possible, the damage induced by the venom of both snakes. We believe that these preliminary studies involving immune response in mice splenocytes may promote a better understanding of Bothrops and Crotalus envenomations.

\section{Materials and methods}

\section{Animals}

Male BALB/c mice (aged 6 to 8 weeks) were raised at the animal facilities of the Oswaldo Cruz Foundation (Rio de Janeiro, Brazil) and maintained at the animal facilities of the Aggeu Magalhães Research Center of the Oswaldo Cruz Foundation in Recife, Brazil. All mice were treated and sacrificed in accordance with the Oswaldo Cruz Foundation Commission for Experiments with Laboratory Animals (Ministry of Health, Brazil, 0266/05).

\section{Preparation of B. erythromelas and C.d. cascavella venom}

Male and female specimens of $B$. erythromelas and C. $d$. cascavella snakes were milked, and their venom was maintained at $4^{\circ} \mathrm{C}$ until use. The protein concentration of the venom was analyzed by the Lowry test. ${ }^{20}$

\section{Preparation of splenocytes}

Splenocytes were obtained according to Pereira et al. ${ }^{21}$ After euthanizing each animal with carbon dioxide $\left(\mathrm{CO}_{2}\right)$ gas, the spleen was removed aseptically and placed in a Falcon tube containing RPMI 1640 with fetal calf serum (complete medium). In a vertical flow, each spleen was transferred to a Petri dish, where it was macerated. The cell suspensions obtained were transferred to Falcon tubes containing approximately $10 \mathrm{~mL}$ of incomplete medium per spleen, and centrifuged at $4^{\circ} \mathrm{C}, 200 \times \mathrm{g}$ for 5 minutes. After discarding the supernatant, distilled water was added to the sediment to promote lysis of red blood cells. The supernatant, containing no cellular debris, was collected and centrifuged at $4^{\circ} \mathrm{C}, 200 \times \mathrm{g}$ for 5 minutes. The sediment (containing cells) was resuspended in complete RPMI 1640. An aliquot of each cell suspension was separated and diluted in trypan blue to be quantified in a Neubauer chamber, and cell viability was determined.

\section{In vitro cytotoxicity assays}

The cytotoxicity of the venom was determined using BALB/c mice splenocytes $\left(6 \times 10^{5}\right.$ cells/well $)$ cultured in 96 -well plates in RPMI 1640 media (Sigma-Aldrich Chemical Co, St Louis, MO, USA) supplemented with 10\% fetal bovine serum (FCS; Cultilab, Campinas, SP, Brazil) and $50 \mu \mathrm{g} / \mathrm{mL}$ of gentamycin (Novafarma, Anápolis, GO, Brazil). Each venom was evaluated at six concentrations $(1,5,10,25,50$, and $100 \mu \mathrm{g} / \mathrm{mL}$ ) in triplicate on two independent assays. Cultures were incubated in the presence of ${ }^{3} \mathrm{H}$-thymidine (Amersham Biosciences) $(1 \mu \mathrm{Ci} /$ well $)$ for 24 hours at $37^{\circ} \mathrm{C}$ and $5 \% \mathrm{CO}_{2}$. After this period, the content of the plate was harvested to determine the ${ }^{3} \mathrm{H}$-thymidine $\left(\left[{ }^{3} \mathrm{H}\right] \mathrm{TdR}\right)$ incorporation using a beta-radiation counter ( $\beta$-matrix 9600, Packard). The toxicity of the venom was determined by comparing the percentage of ${ }^{3} \mathrm{H}$-thymidine incorporation (as an indicator of cell viability) of venom-treated wells in relation to untreated wells. Saponin $(0.05 \%)$, a known cytotoxic compound, was used as a positive control. Concanavalin A (Con A) and Phytohemagglutinin (PHA) were used as references for immunological assays. Noncytotoxic concentrations were defined as those causing a reduction of ${ }^{3} \mathrm{H}$-thymidine incorporation below $30 \%$ in relation to untreated controls.

\section{Measurement of cytokine levels in splenocyte supernatants}

Splenocytes were cultured in 24-well plates (TPP) at a density of $10^{6}$ cells/well. Cytokines were quantified in 24,48 , 72 hours, and 6 day supernatants from cultures stimulated with $B$. erythromelas snake venom $(100,10$, and $1 \mu \mathrm{g} / \mathrm{mL})$, C. d. cascavella snake venom $(100,10$, and $1 \mu \mathrm{g} / \mathrm{mL})$, Con A $(2.5 \mu \mathrm{g} / \mathrm{mL})$, PHA $(5 \mu \mathrm{g} / \mathrm{mL})$, or maintained only in culture medium (control). The levels of IL-2, IL-6, IL-10, and IFN- $\gamma$ were measured by sandwich ELISA, according to the manufacturer's suggested protocols. The monoclonal antibodies used were from Kit OptEIA (BD Biosciences), having previously been titered. Plates with 96 wells (Nalge Nunc International Corporation) were sensitized with specific 
anticytokine antibodies (according to the manufacturer's instructions) and incubated "overnight" at $4^{\circ} \mathrm{C}$. Cytokine standards were added after serial dilution from their initial concentrations $(800,10000,8000$, and $8000 \mathrm{pg} / \mathrm{mL}$ for IL-2, IL-6, IL-10, and IFN- $\gamma$, respectively). After washes, $50 \mu \mathrm{L}$ of all samples and standards were added in duplicate and the plates incubated for 2 hours at room temperature. Subsequently, the specific antibodies were combined with biotin (according to the manufacturer's instructions) and incubated for 1 hour 30 minutes at room temperature. Revealer solution containing 2.2-azino-bis (3-ethylbenzothiazoline-6-sulfonic acid) diammonium salt was added. The reaction was blocked with $1 \mathrm{M}$ sulfuric acid, and the reading was carried out in a spectrophotometer (Bio-Rad 3550 , Hercules, CA, USA) at $415 \mathrm{~nm}$. Sample concentrations were calculated in the linear region of the titration curve of cytokine standards, and final concentrations were expressed in $\mathrm{pg} / \mathrm{mL}$, using the Microplate Manager Version 4.0 software (Bio-Rad Laboratories).

\section{Analysis of cell viability by annexin V-FITC and propidium iodide staining}

Splenocytes were treated with $B$. erythromelas venom (100, 10, and $1 \mu \mathrm{g} / \mathrm{mL}), C$. d. cascavella venom $(100,10$, and $1 \mu \mathrm{g} / \mathrm{mL})$, Con A $(2.5 \mu \mathrm{g} / \mathrm{mL})$, and PHA $(5 \mu \mathrm{g} / \mathrm{mL})$. These treated cells were maintained in culture in 24-well plates (TPP) for 24 hours to analyze their cell viability. Untreated cells (control) were used as a negative control. Following this, lymphocytes were centrifuged at $4{ }^{\circ} \mathrm{C}$, $450 \times \mathrm{g}$ for 10 minutes. After discarding the supernatant, $1 \mathrm{~mL}$ of PBS $1 \mathrm{X}$ was added to the sediment, and the mixture was centrifuged at $4^{\circ} \mathrm{C}, 450 \times \mathrm{g}$ for 10 minutes. After discarding the supernatant, the pellet was resuspended in a binding buffer (10 mM HEPES [pH 7.4], $150 \mathrm{mM} \mathrm{NaCl}, 5 \mathrm{mM} \mathrm{KCl}, 1 \mathrm{mM} \mathrm{MgCl}$, and $1.8 \mathrm{mM}$ $\mathrm{CaCl}_{2}$ ), and annexin $\mathrm{V}$ conjugated with fluorescein isothiocyanate (FITC) (1:500) and propidium iodide (PI, $20 \mu \mathrm{g} / \mathrm{mL} ; 10^{6}$ cells) was added to each labeled cytometer tube. Flow cytometry was performed on a FACSCalibur (Becton Dickinson Biosciences, Mountain View, CA, USA) and analyzed using CellQuest Pro software (Becton Dickinson). Results analysis was performed on graphs by dot plot. Double negatives (annexin-FITC- $\mathrm{PI}^{-}$) were considered viable cells. Annexin-FITC ${ }^{+} / \mathrm{PI}^{-}$represented splenocytes in the early stage of apoptosis. Double positive annexin-FITC $/ \mathrm{PI}^{+}$were considered to be spleen cells in the late stage of apoptosis and only $\mathrm{PI}^{+}$cells were considered necrotic.

\section{In vitro nitrite analysis}

Splenocytes were used to evaluate the concentration of nitrite after treatment with $B$. erythromelas venom $(100,10$, and $1 \mu \mathrm{g} / \mathrm{mL}), C . d$. cascavella venom (100, 10 , and $1 \mu \mathrm{g} / \mathrm{mL})$, Con A $(2.5 \mu \mathrm{g} / \mathrm{mL})$, PHA $(5 \mu \mathrm{g} / \mathrm{mL})$, or maintained only in culture medium (control) after 24, 48, $72 \mathrm{~h}$, and 6 days of incubation. Culture media were carefully collected for subsequent measurement by the colorimetric Griess method (Ding et al). ${ }^{22} \mathrm{NO}$ concentration was estimated by the standard curve $(3.12-100 \mu \mathrm{mol} / \mathrm{mL})$, and the reading was carried out in a spectrophotometer (Bio-Rad 3550) at $490 \mathrm{~nm}$.

\section{Statistical analysis}

Data were analyzed using nonparametric tests. Differences among groups were analyzed by one-way analysis of variance (ANOVA) followed by either Tukey's $t$-test or a KruskalWallis nonparametric test. All results were expressed as mean values of groups \pm standard deviation of four independent experiments per group and were analyzed considering the value of $P<0.05$ as statistically significant.

\section{Results}

The cytotoxicity threshold was expressed as the highest concentration tested that was not cytotoxic for the splenocytes. Saponin was used as a positive control. Results showed that Saponin $(0.05 \%)$, which is known for its cytotoxity, demonstrated a higher inhibition. Con A and PHA, used as references for immunological assays, did not show toxic activity at 50 to $1 \mu \mathrm{g} / \mathrm{mL}$ concentrations for Con A and at neither concentration for PHA. Both B. erythromelas and C. $d$. cascavella venom was cytotoxic above $1 \mu \mathrm{g} / \mathrm{mL}$ concentration, indicating the higher toxic effect induced by the snake venom in splenocyte cultures (Table 1). Because of the higher toxic effect induced by the venom of both snakes,

Table I Cytotoxic effect induced by Bothrops erythromelas and Crotalus durissus cascavella venom. Assay using splenocytes of $B A L B / c$ mice cultured in vitro with $B$. erythromelas and $C$. d. cascavella venom, Con A, PHA, saponin, and unstimulated cells stained with $\left[{ }^{3} \mathrm{H}\right]$-thymidine

\begin{tabular}{lllllll}
\hline Compounds & \multicolumn{7}{c}{ Lectin concentrations $(\mu \mathrm{g} / \mathrm{mL})$} \\
\hline & 100 & 50 & 25 & 10 & 5 & I \\
B. erythromelas & 62 & 55 & 44 & 35 & 33 & - \\
C. d. cascavella & 61 & 56 & 53 & 36 & 31 & - \\
Con A & 58 & - & - & - & - & - \\
PHA & - & - & - & - & - & - \\
Saponin & 94 & 91 & 90 & 89 & 88 & 88 \\
\hline
\end{tabular}

Notes: *Percent of cellular proliferation inhibition. $(-)$ = Noncytotoxic concentrations were defined as those causing a reduction of $\left[{ }^{3} \mathrm{H}\right]$-thymidine incorporation below $30 \%$ in relation to untreated controls. 
all immunomodulatory assays in this study (ELISA, nitrite detection, and flow cytometry) were performed using a nontoxic dose, ie, $1 \mu \mathrm{g} / \mathrm{mL}$.

\section{Snake venom promoted different values to IFN- $\gamma$ production}

Immunological investigations of splenocytes stimulated in vitro with $B$. erythromelas snake venom were performed comparing this group with splenocytes stimulated with C. d. cascavella snake venom. Because of their immunological properties, Con A and PHA mitogens were used as positive controls, and unstimulated cells (cells + medium) were used as a negative control. Four experimental times, ie, 24, 48, 72 hours, and 6 days, were used in our assays. In 24 hours, Con A $(2149 \pm 311)$ showed higher and statistically significant values in relation to the control $(P \leq 0.05)$. However, at the same time, $B$. erythromelas venom (1422 \pm 480 and $1214 \pm 380$ at 100 and $1 \mu \mathrm{g} / \mathrm{mL}$ concentrations, respectively) and $C$. $d$. cascavella (1234 \pm 348 at $1 \mu \mathrm{g} / \mathrm{mL}$ concentration) induced higher, but not statistically significant, IFN- $\gamma$ production. At 48 hours, only $C$. $d$. cascavella (1374 \pm 288 at $1 \mu \mathrm{g} / \mathrm{mL}$ ) showed statistically significant values in relation to the control $(P \leq 0.05)$. The time of greatest IFN- $\gamma$ production for all stimuli in vitro was 72 hours (Figure $1 \mathrm{~A}-\mathrm{E}$ ). At this time, we observed that both $B$. erythromelas and $C$. d. cascavella (at $100 \mu \mathrm{g} / \mathrm{mL}$ ) showed significant values (Figure 1D-E). Finally, after 6 days of assay, only Con A (6032 \pm 2545$)$ and C. d. cascavella $(3090 \pm 601$ at $100 \mu \mathrm{g} / \mathrm{mL})$ showed significant IFN- $\gamma$ production $(P \leq 0.05)$. As shown in Figure 1 , IFN- $\gamma$ levels in supernatant cultures showed peak values at 72 hours
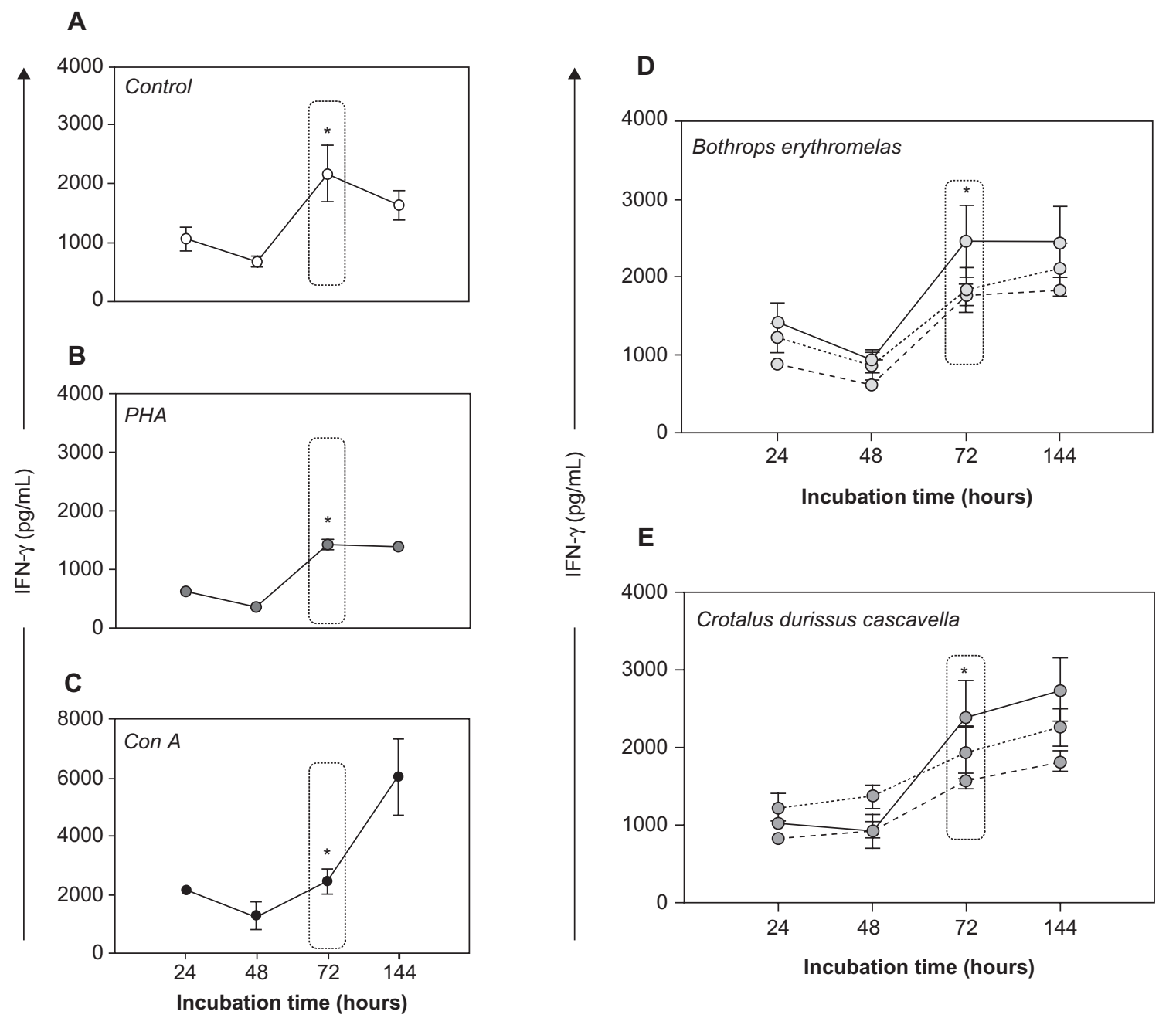

Figure I Profile of IFN- $\gamma$ production by BALB/c mice splenocytes following in vitro stimuli with snake venom.

Notes: Splenocytes were incubated under distinct experimental conditions, including: A) the absence of exogenous stimuli - control culture ( $\bigcirc)$; B) in the presence of PHA (O); C) in the presence of Con A (O); D) in the presence of distinct concentrations (- $100 \mu \mathrm{g} / \mathrm{mL}$, --- $10 \mu \mathrm{g} / \mathrm{mL}$, and --- I $\mu \mathrm{g} / \mathrm{mL})$ of $B$. erythromela $(\mathrm{O})$; or E) C. d. cascavella venons (O). Data are expressed as mean levels of IFN- $\gamma(\mathrm{pg} / \mathrm{mL}) \pm$ standard error. Rectangles highlight the data points at 72 hours of incubation, identified as the first statistically significant $(P<0.05)$ time point for IFN- $\gamma$ production as compared with 24 and 48 hours of incubation (*) and therefore selected for further analysis. Horizontal bars represent the average of four independent experiments per group. 
of assay. Thus, 72 hours was the time chosen to analyze other cytokines in this study, such as IL-2, IL-6, IL-10, and NO.

\section{Profile of cytokine release and comparative analysis at 72 hours of assay}

Other cytokines, such as IL-2, IL-6, IL-10, and NO, were measured in our study. IL-2 was not produced at significant levels for any treatment with snake venom at all experimental times. Only Con A showed statistically significant induction of production of this cytokine at 24,48 , and 72 hours $(628 \pm 42$, $768 \pm 13$, and $151 \pm 1.9$ and $P<0.05$, respectively) (data not shown). Similar to IFN- $\gamma$, IL-6 was also produced in statistically significant values by $B$. erythromelas $(13.235 \pm 1850$ at $1 \mu \mathrm{g} / \mathrm{mL})$ and by C.d. cascavella $(11606 \pm 1038$ at $10 \mu \mathrm{g} / \mathrm{mL})$ at 72 hours of assay. The same result was observed for IL-10 and NO production at 72 hours of assay (Figure 2B and C). IL-10 was detected in splenocytes stimulated with $B$. erythromelas venom (100 and $10 \mu \mathrm{g} / \mathrm{mL}$ concentrations $)$ and C. d. cascavella venom $(1 \mu \mathrm{g} / \mathrm{mL})$ when compared with the control (Figure 2B). Although NO production showed higher levels, only $B$. erythromelas venom $(1 \mu \mathrm{g} / \mathrm{mL})$ showed higher values $(P \leq 0.05)$ in relation to the control at 72 hours of assay (Figure $2 \mathrm{C}$ ). In addition, we could also see that although there were no differences among venom stimulus in relation to IFN- $\gamma$ production (Figure $2 \mathrm{~A}$ ), we observed a dichotomy in the synthesis of NO and IL-10 at 72 hours of assay. In fact, when we increased doses of venom from $B$. erythromelas, a gradual increase in IL-10 production and a decrease in NO release occurred (Figure 2B and C). The opposite effect was observed, ie, an increased $C$. $d$. cascavella dose induced a lower IL-10 production and a higher NO release (Figure 2B and C). These observations are very important for understanding venom molecular differences and signaling mechanisms in mice splenocytes.

\section{Analysis of IFN-g/IL- I 0 balance between snake venom}

An imbalance in the ratio between proinflammatory and antiinflammatory events is possible. To analyze this characteristic, we assessed the balance in the synthesis of IFN/IL-10 at 72 hours of in vitro stimuli. Figure 3 shows that although no significant difference was observed in this ratio, high doses of $B$. erythromelas venom $(100 \mu \mathrm{g} / \mathrm{mL})$ were able to promote an immunoregulatory effect, characterized by an inverse relationship in the synthesis of IFN- $\gamma$ and IL-10.

\section{Profile of cell viability indicated higher necrosis induced by $B$. erythromelas venom}

After the cytotoxicity analysis, we investigated possible cell damage induced by snake venom in mice splenocytes. For this analysis we used apoptosis, late apoptosis, and necrosis parameters to indicate the induction of death and cellular damage promoted by the venom of both snakes (Figure 4A-E). The absence of exogenous stimuli was used as control. Figure $4 \mathrm{~A}$ shows the cell viability status of BALB/c mice splenocytes following 24 hours of in vitro stimuli with snake venom. The data analysis indicated that $B$. erythromelas (at 100,10 , and $1 \mu \mathrm{g} / \mathrm{mL}$ concentrations) induced higher late apoptosis and necrosis (at 100 and $10 \mu \mathrm{g} / \mathrm{mL}$ ) (Figure 4C and D). On the other hand, $C$. $d$. cascavella venom only showed higher necrosis induction at $1 \mu \mathrm{g} / \mathrm{mL}$ concentration (Figure 4D). Comparison between the venom of both snakes also showed higher late apoptosis induced by $B$. erythromelas
A

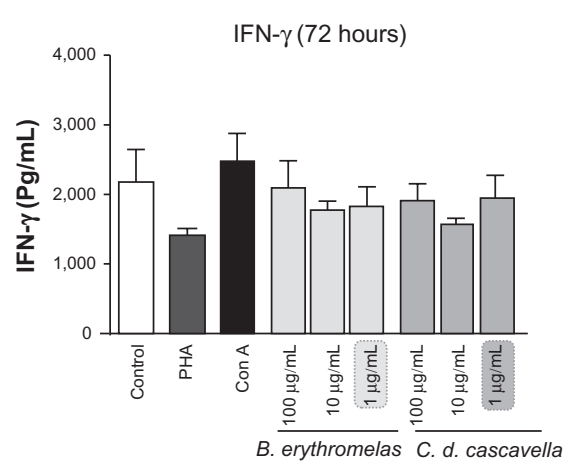

B

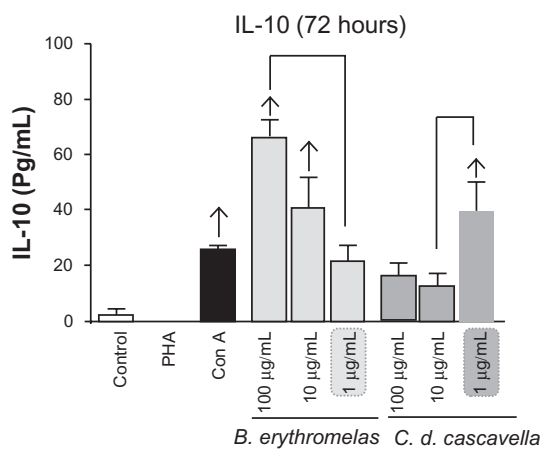

C

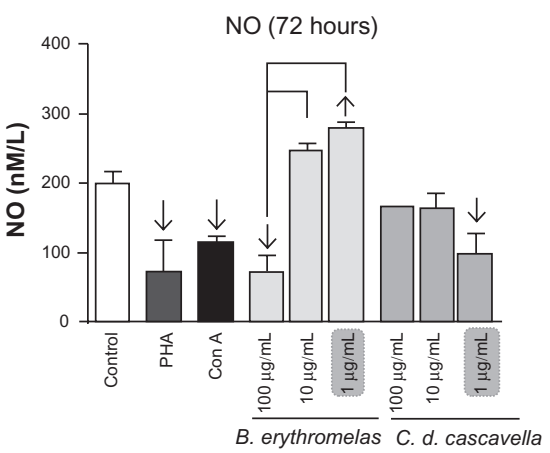

Figure 2 Comparative analysis of IFN- $\gamma$, NO, and IL- 10 production by BALB/c mice splenocytes following 72 hours of in vitro stimuli with snake venom. Notes: Splenocytes were incubated under distinct experimental conditions, including the absence of exogenous stimuli - control culture ( $\square$ ); in the presence of PHA ( $\square$ );

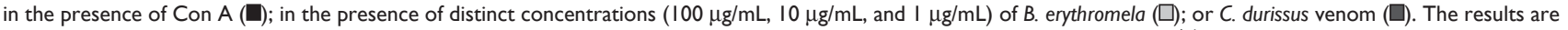
expressed as mean levels of IFN- $\gamma, \mathrm{NO}$, and IL-IO (pg/mL) \pm standard error. Significant differences at $P<0.05$ are highlighted by $\uparrow \downarrow$ as compared with control cultures and by connecting lines for intragroup comparisons. Dashed rectangles highlight the venom concentration $(I \mu g / \mathrm{mL})$ that induced a dichotomous profile between $B$. erythromela (proinflammatory) and C. d. cascavella (regulatory). ND = not done. Horizontal bars represent the average of four independent experiments per group. 

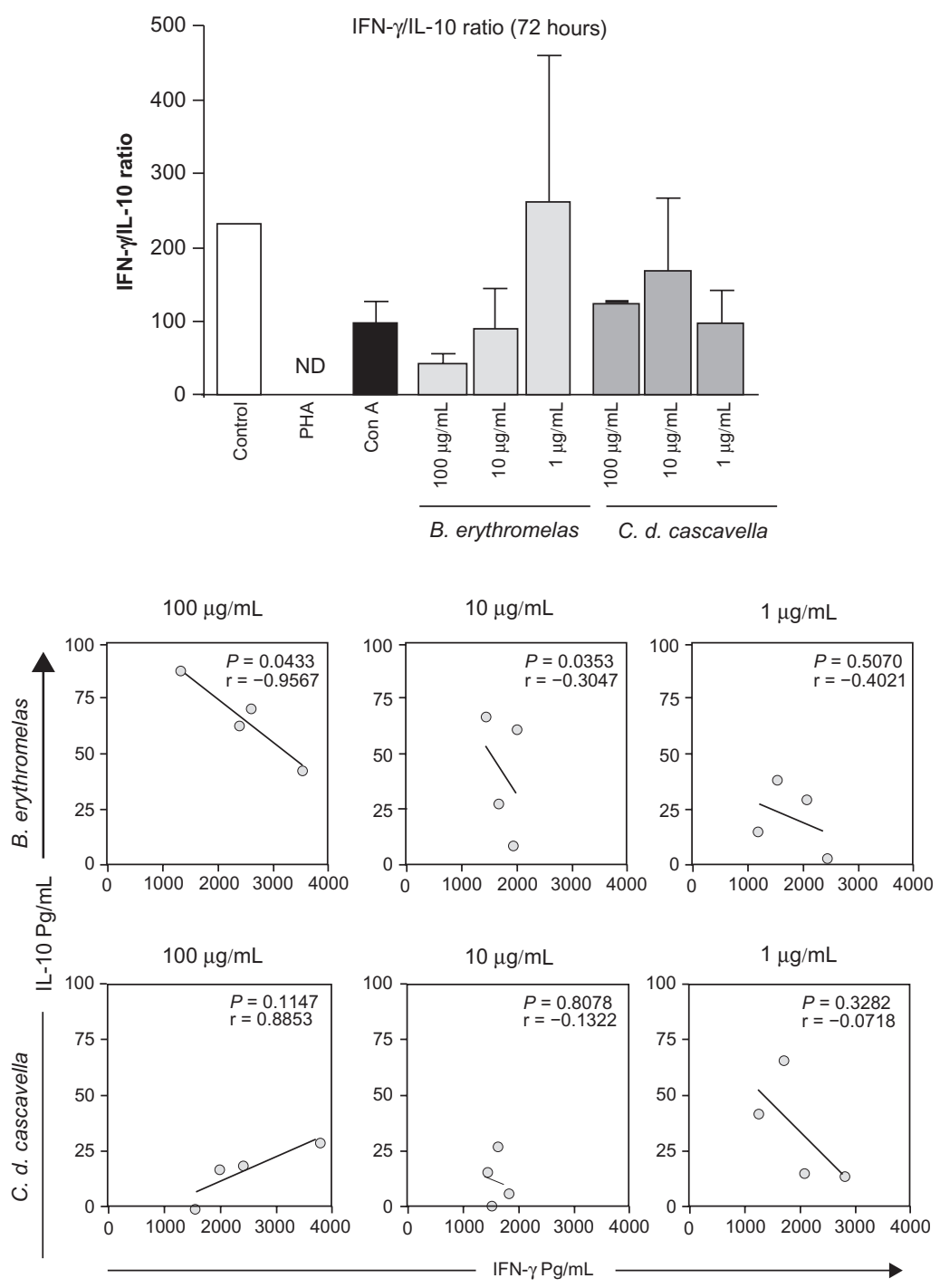

Figure 3 Analysis of IFN-g/LL-I0 balance produced by BALB/c mice splenocytes following 72 hours of in vitro stimuli with snake venom.

Notes: Top panel represents the IFN- $\gamma /$ IL- 10 ratio, considering the distinct experimental conditions, including absence of exogenous stimuli - control culture ( $\square$ ); presence of Con A $(\square)$; presence of distinct concentrations $(100 \mu \mathrm{g} / \mathrm{mL}, 10 \mu \mathrm{g} / \mathrm{mL}$, and I $\mu \mathrm{g} / \mathrm{mL})$ of B. erythromela $(\square)$; or $C$. d. cascavella venom $(\square)$. The results are expressed as mean IFN- $\gamma / \mathrm{IL}-10$ ratio \pm standard error. Bottom panels represent correlation analysis between IFN- $\gamma(\mathrm{pg} / \mathrm{mL})$ and IL- 10 (pg/mL) following in vitro stimuli with $B$. erythromela $(\mathrm{O})$ or C. d. cascavella $(\mathrm{O})$ at distinct concentrations $(100 \mu \mathrm{g} / \mathrm{mL}, 10 \mu \mathrm{g} / \mathrm{mL}$, and I $\mu \mathrm{g} / \mathrm{mL}$ ). Correlation indices ( $\mathrm{r}$ and $P$-values) are provided in the figure. Significance was considered at $P<0.05$ and highlighted in bold. Horizontal bars represent the average of four independent experiments per group.

(at $1 \mu \mathrm{g} / \mathrm{mL}$ concentration) in relation to $C$. $d$. cascavella venom (Figure 4C).

\section{Discussion}

Snakes of the genera Bothrops and Crotalus are responsible for the majority of the ophidian accidents in Latin America and, specifically, Brazil. In humans and experimental animals, Bothrops envenomation induces systemic hemorrhage and blood incoagulability in addition to intense tissue damage at the site of injection. Symptoms are due to the presence of a variety of toxins in the venom. ${ }^{13,23}$ On the other hand, Crotalus envenomation does not induce a significant inflammatory reaction at the site of the bite but exerts severe systemic neuro-, nephro-, hepato-, and myotoxic effects. ${ }^{24}$

Many studies have investigated immunomodulatory effects induced by the venom of different snakes, and these immunological alterations were observed as both cellular and humoral responses. ${ }^{25,26}$ The aim of this study was the same, but before analyzing immunological aspects and the stimulation profile exerted by B. erythromelas and C. d. cascavella snake venom, it was necessary to investigate of cytotoxicity levels promoted by the venom of both snakes against mice splenocytes.

We used tritiate thymidine $\left(\left[{ }^{3} \mathrm{H}\right] \mathrm{TdR}\right)$ in our assays, given that thymidine acts through the incorporation of 
A

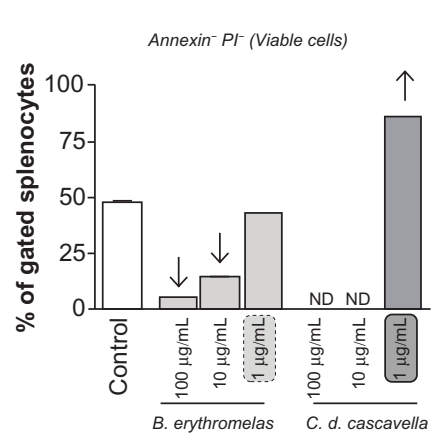

B

Annexin+ Pl- (Early Apoptototic cells)

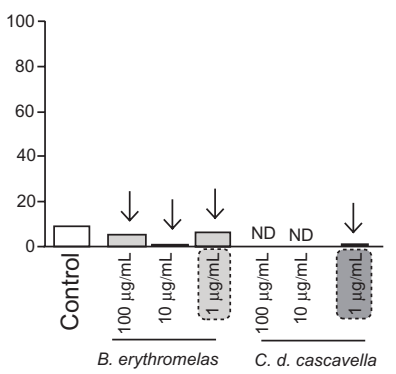

C

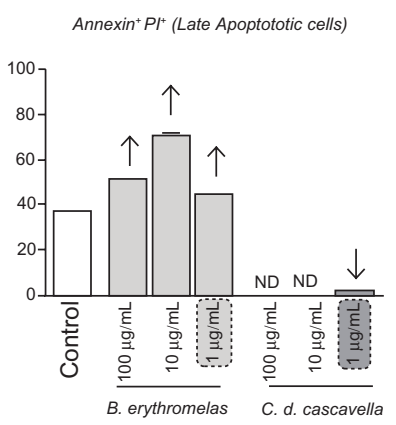

D

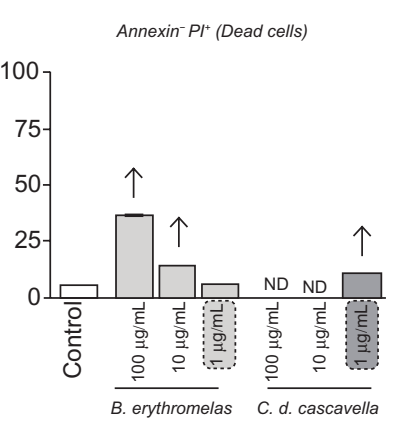

E
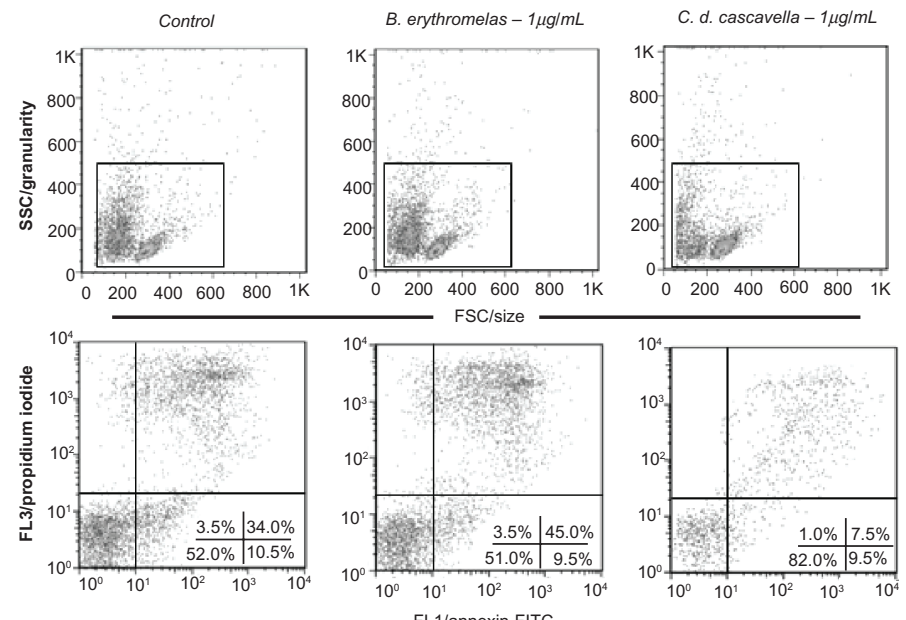

- FL1/annexin-FITC

Figure 4 Profile of cell viability and apoptotic and necrotic BALB/c mice splenocytes following in vitro stimuli with snake venom.

Notes: Top panel represents the cell viability status, considering the distinct experimental conditions, including absence of exogenous stimuli - control culture ( $\square$ ) and presence of distinct concentrations $(100 \mu \mathrm{g} / \mathrm{mL}, 10 \mu \mathrm{g} / \mathrm{mL}$, and I $\mu \mathrm{g} / \mathrm{mL})$ of B. erythromela $(\square)$ or $C$. d. cascavella venom ( $\square$ ). The results are expressed as mean percentage of viable cells (annexin- $\mathrm{Pl}^{-}$), early apoptotic cells (annexin ${ }^{+} \mathrm{Pl}^{-}$), late apoptotic cells (annexin ${ }^{+} \mathrm{Pl}^{+}$), and dead cells (annexin $\left.{ }^{-} \mathrm{Pl}^{+}\right) \pm$standard error. Bottom panels display representative dot plot distributions of cell phenotypes highlighting the percentage of viable and late apoptotic cells. Significant differences at $P<0.05$ are highlighted by $\uparrow \downarrow$ as compared with control cultures. Horizontal bars represent the average of four independent experiments per group.

tritium into the DNA of cells and is the most commonly used technique today for proliferation. This method is effective for evaluation of specific lymphocyte cytotoxicity. ${ }^{27}$ Our results showed higher cytotoxic effects induced by snake venom above a $1 \mu \mathrm{g} / \mathrm{mL}$ concentration. Lomonte et $\mathrm{al}^{28}$ investigating Bothrops asper snake venom, showed similar results and affirmed that the venom displayed in vitro cytotoxicity in spleen cells in a dose- and time-dependent manner. Torres et $\mathrm{al}^{29}$ also showed that the PLA $\mathrm{P}_{2}$ fraction from Bothrops marajoensis snake venom presented higher cytotoxicity in murine macrophages, including membrane disruption and cell lysis. In addition, Crotalus durissus terrificus venom induced cytotoxic effects in splenocytes treated in vitro with a $5 \mu \mathrm{g} / \mathrm{mL}$ dose and induced decreased cell viability. ${ }^{25}$

Many studies have described the involvement of cytokines in envenomation, including snake, scorpion, and spider venom models. ${ }^{30-32}$ To identify the impact of snake venom in terms of inflammatory activity, we analyzed the profile of IFN- $\gamma$, IL-2, IL-6, IL-10, and NO production in mice splenocytes stimulated in vitro with $B$. erythromelas and C. d. cascavella snake venom. In our study, we observed that the best time of culture to analyze cytokine release was 72 hours. In fact, venom from both snakes was capable of inducing IFN- $\gamma$, IL-6, IL-10, and NO production, but this cytokine release showed different results between the different types of venom.

Our data showed that IL-2 production was not significantly induced by either type of snake venom. However, the venom of both snakes induced similar IFN- $\gamma$ and IL-6 production. B. erythromelas induced more IL-10 production than $C . d$. cascavella, and only B. erythromelas venom induced statistical levels of NO. Furthermore, a dichotomy was observed in the venom, indicating possible molecular 
differences and signaling mechanisms induced by the venom of both snakes.

Similar results were demonstrated by Rangel-Santos et al. ${ }^{25}$ These authors affirm that splenocytes treated with Crotalus $d$. terrificus venom did not show IL-2 and IL-10 cytokine release. In fact, other studies have demonstrated, through in vivo and in vitro assays, the same profile of cytokine release observed in our study. Escocard et al ${ }^{30}$ showed IL-6 production induced by crude venom of Bothrops atrox; Petricevich et $\mathrm{al}^{33}$ investigating the venom of Bothrops asper and B. jararaca, demonstrated that the venom of both snakes induced prominent elevations on the production of IL-6, IL-10, and IFN- $\gamma$, and Lomonte et $\mathrm{al}^{28}$ showed that injection of Bothrops asper venom into mouse paws also invoked increased levels of IL-6 in the serum.

Higher NO release observed in splenocytes stimulated in vivo with $B$. erythromelas venom may be a consequence of characteristics induced by this venom in host tissue, such as damage, prominent necrosis, hemorrhage, and edema, which are characteristics of Bothrops envenomation. ${ }^{34,35}$ Furthermore, experimental studies showed that $B$. asper venom induces phagocytosis and triggers microbicidal functions of peritoneal leukocytes in vivo with a consequent increase in the production of hydrogen peroxide and NO by macrophages, followed by the generation of toxic peroxynitrites. ${ }^{26}$ In fact, NO is also produced during the host response evoked by $B$. asper venom. This venom induced the synthesis of NO following intramuscular and intraperitoneal injections in mice, mainly through induction of expression of the inducible nitric oxide synthase (iNOS) promoted by higher IFN- $\gamma$ release. In addition, a protective role of $\mathrm{NO}$ was demonstrated against the lethal activity of this venom. ${ }^{26,36}$ Barros et $\mathrm{al}^{37}$ also showed similar results, indicating that low IFN- $\gamma$ production was followed by undetected NO levels in supernatant cultures. These studies showed similar proinflammatory responses as achieved in our assays.

Distinct actions of both $B$. erythromelas and C. $d$. cascavella venom shown in this study may be explained by the different toxin composition and clinical manifestations presented by this venom in envenomated humans and mice, as previously explained. Other Bothrops genus species, such as B. asper, B. jararaca, and B. atrox, show similar induction of histamine, bradykinin, eicosanoids, prostaglandin, and cytokine production involved in Bothrops envenomations. ${ }^{28,36,37}$ Beyond, similar to our data, other studies affirm the higher Th1 response induced by Bothrops envenomations promoted in association with a higher proinflammatory response observed on ophidian envenomation. ${ }^{33,36}$ Although Crotalus envenomations induce similar hemorrhagic and tissue-damaging effects observed in Bothrops envenomations, the production of prostaglandins (potent proinflammatory mediators) induced by Crotalus venom is still unclear. ${ }^{24,38}$ Beyond that, some studies have shown the anti-inflammatory profile of this venom. ${ }^{39,40}$

Although many stimuli can induce immunomodulatory responses, eg, snake venom, it is necessary to verify whether this response is beneficial for the stimulated immune cell, because some studies affirm that specific stimuli (biological or chemical) can induce damage, such as apoptosis or necrosis, on target cells through excessive free radical accumulation. ${ }^{41,42}$ In our cell viability assay, B. erythromelas induced more cell damage than $C$. $d$. cascavella venom. Teixeira et $\mathrm{a}^{43}$ also reported similar results showing depletion of neutrophils in mice treated with $B$. asper venom and amyotoxic $\mathrm{PLA}_{2}$ fraction. In addition, Angulo and Lomonte, ${ }^{44}$ analyzing the mechanism of action of myotoxin II, a phospolipase $\mathrm{A}_{2}$ of $B$. asper venom, showed that this toxin can induce necrotic cell death through degenerative events related to $\mathrm{Ca}^{2+}$ influx. Studies analyzing Crotalus venom effects were performed with isolated fraction (toxins) of this venom, and it has been shown that these toxins cause a reduction in the resting potential of the membrane and an increase in membrane conductance. ${ }^{45,46}$ Rangel-Santos et $\mathrm{al}^{25}$ showed in their assays that Crotalus $d$. terrificus venom induced higher inhibition of the cellular proliferative response, in cultures stimulated by Con A, in both crude venom and crotoxin (isolated fraction). However, their cell viability test did not show significant results. In our study we used total Crotalus venom, and we suggest that this methodology may be key to promoting low cell damage in comparison with $B$. erythromelas. Many studies have investigated the cell damage induced by this viperid snake venom, correlating the role of venom toxins with inflammatory responses. Díaz et al, ${ }^{47}$ treating human endothelial cells with $\mathrm{BaP} 1$, observed that this venom fraction induces apoptosis through caspase- 8 activation. In addition, Gallagher et $\mathrm{al}^{48}$ observed in their study that fibroblasts treated with jararhagin activated an apoptotic cascade through death receptor (extrinsic) apoptosis pathways.

Snake venom is very complex, containing hundreds of biologically active compounds associated with the inflammatory process. ${ }^{48}$ In this study we observed that B. erythromelas and C. d. cascavella venom induced a marked immunomodulatory response in vitro through cytokines and NO production. However, it is evident that B. erythromelas promotes a proinflammatory profile and that $C$. $d$. cascavella venom has the opposite effect, ie, is anti-inflammatory. 
We suggest that these data can enhance our understanding of immunological consequences induced by ophidian envenomation, especially concerning South American species, and may promote a better understanding for future therapeutic strategy by anti-ophidic venom treatment.

\section{Acknowledgments}

We are grateful to Lucas Ferreira da Rocha and Maria da Conceição Batista for technical assistance. This work was supported by the Fundação de Amparo à Ciência e Tecnologia do Estado de Pernambuco (FACEPE processo APQ-0493-2.11/08) and the Aggeu Magalhães Research Center of the Oswaldo Cruz Foundation in Recife, Brazil (CPqAM/FIOCRUZ).

\section{Disclosure}

No conflicts of interest were declared in relation to this paper.

\section{References}

1. Kasturiratne A, Wickremasinghe AR, Silva N, et al. The global burden of snakebite: a literature analysis and modelling based on regional estimates of envenoming and deaths. PLoS Med. 2008;5(11):e218.

2. Harrisson RA, Hargreaves A, Wagstaff SC, Faragher B, Laloo DG. Snake envenoming: a disease of poverty. Plos Negl Trop Dis. 2009;3(12): e569.

3. Ministério da Saúde de Brasil. Manual de diagnóstico e tratamento de acidentes por animais peçonhentos. Fundação Nacional de Saúde. 2001.

4. Teixeira CFP, Cury Y, Oga S, Jancar S. Hyperalgesia induced by Bothrops jararaca in rats: role of eicosanoids and platelet activating factor. Toxicon. 1994;32:419-426.

5. Nascimento NG, Sampaio MC, Olivo RA, Teixeira C. Contribution of mast cells to the oedema induced by Bothrops moojeni snake venom and a pharmacological assessment of the inflammatory mediators involved. Toxicon. 2010;55:343-352.

6. Santoro ML, Sousa-e-Silva MC, Gonçalves LR, et al. Comparision of the biological activities in venom from three subspecies of the South American rattlesnake (Crotalus durissus terrificus, C. durissus cascavella and C. durissus collilineatus). Comp Biochem Physiol C Pharmacol Toxicol Endocrinol. 1999;122:61-73.

7. Martins AM, Lima AA, Toyama MH, Marangoni S, Fonteles MC, Monteiro HS. Renal effects of supernatant from macrophages activated by Crotalus durissus cascavella venom: the role of phospholipase A2 and cyclooxygenase. Pharmacol Toxicol. 2003;92:14-20.

8. Bercovici D, Chudziniski AM, Dias NO, et al. A systematic fraction of Crotalus durissus terrificus venom. Mem Inst Butantan. 1987;49: $69-78$.

9. Evangelista JSAM, Martins AMC, Nascimento NRF, et al. Renal and vascular effects of the natriuretic peptide isolated from Crotalus durissus cascavella venom. Toxicon. 2008;52:737-744.

10. Ahlstrom NG, Luginbuhl W, Tisher CC. Acute anuric renal failure after pygmy rattlesnake bite. South Med J. 1991;84:783-785.

11. Martins AM, Monteiro HS, Júnior EO, Menezes DB, Fonteles MC. Effects of Crotalus durissus cascavella venom in the isolated rat kidney. Toxicon. 1998;36:1441-1450.

12. Zamuner SR, Zuliani JP, Fernandes CM, Gutiérrez JM, Teixeira CFP. Inflammation induced by Bothrops asper venom: release of proinflammatory cytokines and eicosanoids, and role of adhesion molecules in leukocyte infiltration. Toxicon. 2005;46:806-813.
13. Chaves F, Teixeira CFP, Gutiérrez JM. Role of TNF- $\alpha$, IL-1 $\beta$ and IL-6 in the local tissue damage induced by Bothrops asper snake venom: an experimental assessment in mice. Toxicon. 2005;45:171-178.

14. Teixeira CFP, Chaves F, Zamunér SR, et al. Effects of neutrophil depletion in the local pathological alterations and muscle regeneration in mice injected with Bothrops jararaca snake venom. Int J Exp Pathol. 2005;86:107-115.

15. Kourilsky P, Truffa-Bachi P. Cytokine fields and the polarization of the immune response. Trends Immunol. 2001;22:502-509.

16. Hoyer KK, Dooms H, Barron L, Abbas AK. Interleukin-2 in the development and control of inflammatory disease. Immunol Rev. 2008;226:19-28

17. Rezaee F, Rellick SL, Piedimonte G, et al. Neurotrophins regulate bone marrow stromal cell IL-6 expression through the MAPK pathway. PLoS ONE. 2010;5(3):e9690.

18. Moore KW, de Waal Malefyt R, Coffman RL, O'Garra A. Interleukin-10 and the interleukin-10 receptor. Annu Rev Immunol. 2001;19: 683-765.

19. Küsters S, Gantner F, Künstle G, Tiegs G. Interferon gamma plays a critical role in $\mathrm{T}$ cell-dependent liver injury in mice initiated by Concanavalin A. Gastroent. 1996;111:462-471.

20. Lowry OH, Rosebrough NJ, Farr AL, Randall RJ. Protein measurement with the Folin-Pheno reagents. J Biol Chem. 1951;193:265-275.

21. Pereira VRA, Lorena VMB, Galvão da Silva AP, et al. Immunization with cytoplasmic repetitive antigen and flagellar repetitive antigen of Trypanosoma cruzi stimulates a cellular immune response in mice. Parasitolgy. 2004;129:563-570.

22. Ding A, Nathan CF, Stuehr DJ. Release of reactive nitrogen intermediates and reactive oxygen intermediates from mouse peritoneal macrophages. J Immunol. 1998;141:2407-2412.

23. Battellino C, Piazza R, Silva AMM, Cury Y, Farsky SHP. Assessment of efficacy of bothropic antivenom therapy on microcirculatory effects induced by Bothrops jararaca snake venom. Toxicon. 2003;41: 583-593.

24. Moreira V, Zamuner SR, Wallace JL, Teixeira CFP. Bothrops jararaca and Crotalus durissus terrificus venoms elicit distinct responses regarding to production of prostaglandins $\mathrm{E} 2$ and $\mathrm{D} 2$, and expression of cyclooxygenases. Toxicon. 2007;49:615-624.

25. Rangel-Santos A, Lima C, Lopes-Ferreira M, Cardoso DF. Immunosupressive role of principal toxin of Crotalus durissus terrificus venom. Toxicon. 2004;44:609-616.

26. Zamuner SR, Gutiérrez JM, Muscará MN, Teixeira SA, Teixeira CFP. Bothrops asper and Bothrops jararaca snake venoms trigger microbicidal functions of peritoneal leukocytes in vivo. Toxicon. 2001;39: 1505-1513.

27. Pechhold K, Craighead N, Wesch D, Kabelitz D. Measurement of cellular proliferation. Met Microb. 2002;32:77-97.

28. Lomonte B, Tarkowski A, Hanson LA. Host response to Bothrops asper snake venom: analysis of edema formation, inflammatory cells and cytokine release in a mouse model. Inflammation. 1993;17: 93-105.

29. Torres AFC, Dantas RT, Toyama MH, et al. Antibacterial and antiparasitic effects of Bothrops marajoensis venom and its fractions: Phospholipase A2 and L-amino acid oxidase. Toxicon. 2010;55:795-804.

30. Escocard RCM, Kanashiro MM, Petretski JH, et al. Neutrophils regulate the expression of cytokines, chemokines and nitric oxide synthase/ nitric oxide in mice injected with Bothrops atrox venom. Immunobiol. 2006;211:37-46.

31. Meki ARMA, El-Dean ZMM. Serum interleukin-1b, interleukin-6, nitric oxide and $\alpha 1$-antitrypsin in scorpion envenomed children. Toxicon. 1998;36:1851-1859.

32. Tambourgi DV, Petricevich VL, Magnoli FC, Assaf SLMR, Jancar S, Dias da Silva W. The endotoxemic-like shock induced by Loxosceles spider venom: pathological changes and putative cytokine mediators. Toxicon. 1998;36:391-403.

33. Petricevich VL, Teixeira CFP, Tambourgi DV, Gutiérrez JM. Increments in serum cytokine and nitric oxide levels in mice injected with Bothrops asper and Bothrops jararaca snake venoms. Toxicon. 2000;38: $1253-1266$. 
34. Gutiérrez JM, Lomonte B. Local tissue damage by Bothrops snake venoms: a review. Mem Inst Butantan. 1989;51:211-223.

35. Gutiérrez JM, Lomonte B. Phospholipase A2 myotoxins from Bothrops snake venoms. In: Kini RM, editor. Venom Phospholipase A2 Enzymes: Structure, Function and Mechanism. Wiley, UK. 1997: 321-352.

36. Chaves F, Teixeira CFP, Gutiérrez JM. Role of nitric oxide in the local and systemic pathophysiological effects induced by Bothrops asper snake venom in mice. Inflamm Res. 2006;55:245-253.

37. Barros SF, Friedlanskaia I, Petricevich VL, Kpinis TL. Local inflammation, lethality and cytokine release in mice injected with Bothrops Atrox venom. Mediators Inflamm. 1998;7:339-346.

38. Kanaoka Y, Urade Y. Hematopoietic prostaglandin D synthase. Prostaglandins Leukot Essent Fatty Acids. 2003;69:163-167.

39. Crocker P, Zad O, Milling T, Maxson T, King B, Whorton E. Human cytokine response to Texas crotaline envenomation before and after antivenom administration. Am J Emerg Med. 2010;28: 871-979.

40. Nunes FP, Sampaio SC, Santoro ML, Sousa-e-Silva MC. Long-lasting anti-inflammatory properties of Crotalus durissus terrificus snake venom in mice. Toxicon. 2007;49:1090-1098.

41. Feske S. Calcium signaling in lymphocyte activation and disease. Nat Rev Immunol. 2007;7:690-702.
42. De Melo CML, Paim BA, Zecchin KG, et al. Cramoll 1,4 lectin increases ROS production, calcium levels and cytokine expression in treated spleen cells of rats. Mol Cell Biochem. 2010;342(1-2):163-169.

43. Teixeira CFP, Zamunér SR, Zuliani JP, et al. Neutrophils do not contribute to localtissue damage, but play a key role inskeletal muscle regeneration, in mice injected with Bothrops asper snake venom. Muscle Nerve. 2003;28:449-459.

44. Angulo Y, Lomonte B. Biochemistry and toxicology of toxins purified from the venom of the snake Bothrops asper. Toxicon. 2009;54: 949-957.

45. Hong SJ, Chang CC. Electrophysiological studies of myotoxin a isolated from prairie rattlesnake (Crotalus viridis viridis) venom on murine skeletal muscle. Toxicon. 1985;23:927-937.

46. Brazil OV, Fontana MD. Toxin as tools in the study of sodium channels distribution in the muscle fibre membrane. Toxicon. 1993;31:1085-1098.

47. Díaz C, Valverde L, Brenes O, Rucavado A, Gutiérrez JJM. Characterization of events associated with apoptosis/anoikis induced by snake venom metalloproteinase $\mathrm{BaP} 1$ on human endothelial cells. Cell Biochem. 2005;94:520-528.

48. Gallagher P, Bao Y, Serrano SMT, et al. Role of the snake venom toxin jararhagin in proinflammatory pathogenesis: In vitro and in vivo gene expression analysis of the effects of the toxin. Arch Biochem Biophys. 2005;441:1-15.

\section{Publish your work in this journal}

The International Journal of Interferon, Cytokine and Mediator Research is an international, peer-reviewed, open-access, online journal. The focus of the journal is to publish original research, reports, editorials, reviews and commentaries on all aspects of interferon, cytokine and mediators of inflammation from labora- tory science to therapeutic indications and clinical studies. The manuscript management system is completely online and includes a very quick and fair peer-review system, which is all easy to use Visit http://www.dovepress.com/testimonials.php to read real quotes from published authors. 